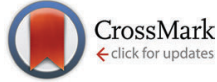

Cite this: Phys. Chem. Chem. Phys., 2014, 16, 27043

Received 26th July 2014, Accepted 27th October 2014

DOI: $10.1039 / c 4 c p 03323$

www.rsc.org/pccp

\section{Plasma modification of poly(2-heptadecyl-4- vinylthieno[3,4-d]thiazole) low bandgap polymer and its application in solar cells $\dagger$}

\author{
Pankaj Attri, ${ }^{a}$ Vishal Bharti, ${ }^{b}$ Young Sun Kim, ${ }^{c}$ Jitender Gaur, ${ }^{* b}$ Suresh Chand, ${ }^{b}$ \\ Gi-Chung Kwon, ${ }^{a}$ Seung-Hyun Lee, ${ }^{d}$ Weontae Lee, ${ }^{e}$ Eun Ha Choi ${ }^{\star a}$ and In Tae Kimc
}

For the first time, we here propose a green methodology to modify a low bandgap polymer for highly efficient solar cells using atmospheric pressure plasma jet or soft plasma operating on different feeding gases (air, $\mathrm{Ar}$ and $\mathrm{N}_{2}$ ). The physical properties of the modified polymer were investigated using conductivity measurements, UV-visible spectroscopy, photoluminescence spectroscopy, X-ray photoelectron spectroscopy, cyclic voltammograms, atomic force microscopy, cathodoluminescence and confocal Raman spectroscopy. Further, we examined the variation of the work function of the polymer before and after plasma treatment using a $\gamma$-focused ion beam. Additionally, photovoltaic cells based on the plasma-modified polymer having ITO/PEDOT:PSS/PHVTT (with or without plasma modification): $\mathrm{PC}_{71} \mathrm{BM} / \mathrm{LiF} / \mathrm{Al}$ configuration were fabricated and then characterized. We found that the power conversion efficiency (PCE) of the plasma-modified polymer increased dramatically as compared to the control polymer (without plasma treatment). PCE of the control polymer was found to be $4.11 \%$, while after air, $\mathrm{Ar}$ and $\mathrm{N}_{2}$ gas plasma treatment the polymer showed PCEs of $4.85 \%, 4.87 \%$ and $5.14 \%$ respectively. Thus, plasma treatment not only alters the surface properties, but also modifies the bulk properties (changes in HOMO and LUMO bandgap level). Hence, this work provides new dimensions to explore more about plasma and polymer chemistry.

\section{Introduction}

The scientific and technological communities have made numerous efforts to create, sustain and apply plasmas due to their several applications in various areas. These associate a number of fields, such as physics, chemistry, biology, engineering, medicine and microbiology, into multidisciplinary research. Due to significant industrial advantages, the atmospheric pressure non-thermal plasma jet (APPJ) has attracted more attention than low-pressure discharge. APPJ has some attractive features for generating unique chemistry. ${ }^{1-3}$ It can produce a stable, uniform and homogenous

\footnotetext{
${ }^{a}$ Plasma BioScience Research Center/Department of Electrophysics, Kwangwoon University, Seoul, Korea 139-701. E-mail: ehchoi@kw.ac.kr; Fax: +82-2-909-1978; Tel: +82-2-3795-1479

${ }^{b}$ Council of Scientific and Industrial Research-National Physical Laboratory, Dr. K. S. Krishnan Marg, New Delhi-110012, India. E-mail: jitender.jnsri@gmail.com ${ }^{c}$ Department of Chemistry, Kwangwoon University, Seoul, Korea 139-701. E-mail: itkim@kw.ac.kr

${ }^{d}$ Graduate School of Information Contents, Kwangwoon University, Seoul, Korea 139-701

${ }^{e}$ Department of Biochemistry, College of Life Science \& Biotechnology, Yonsei University, Seoul, 120-749, Korea

$\dagger$ Electronic supplementary information (ESI) available. See DOI: 10.1039/ с4сp03323j
}

discharge at atmospheric pressure. APPJ can function without a dielectric cover over the electrode, and hence it is free from filaments, arcing and streamers, and can work at low discharge gas temperature, permitting it to treat delicate surfaces without damage. ${ }^{1,4-9}$

Polymer surface modification is a useful method for creating functional polymer surfaces combined with the necessary features of bulk polymers. ${ }^{10-15}$ There are several advantages of the use of plasmas for the treatment of solid surfaces over the conventional solution phase chemistry. Plasma processes are energy efficient and solvent free, rendering them a cost-effective and environmentally friendly alternative to traditional methods. ${ }^{10-12}$ There are many polymers that have been modified using different types of plasma sources. ${ }^{10-15}$ Modification has not been done on low bandgap polymers, nor has their utility in bulk heterojunction solar cells been studied so far. Low bandgap polymers have attracted much attention due to the wide range of small and large applications in organic photovoltaic devices (OPVs). ${ }^{16-25}$ With an aim of enhancing the efficiency of polymer solar cells (PSCs), we developed a polymer, namely poly(2-heptadecyl-4vinylthieno[3,4- $d]$ thiazole) (PHVTT) ${ }^{26}$ and modified it with APPJ in the presence of different feeding gases (air, $\mathrm{Ar}$ and $\mathrm{N}_{2}$ ) and further examined its utility for increasing the efficiency of PSCs. 
This provides details of the mechanism and scope for newer applications in the field of solar cells.

\section{Experimental section}

\subsection{Materials}

The reagents used for the synthesis of the polymer were supplied by Aldrich Chemical Co. (USA). All chemicals and reagents were used without any further purification. The synthesis and characterization of PHVTT $^{26}$ are described in the ESI. $\dagger$

\subsection{Characterization methods}

The synthesized compounds were identified by ${ }^{1} \mathrm{H}$ NMR and ${ }^{13} \mathrm{C}$ NMR spectra, recorded with a Jeol MSL 300 spectrometer. Gel permeation chromatography was carried out with polystyrene standards prepared in THF solutions. A UV-visible S-3100 spectrophotometer having wavelength resolution of $0.95 \mathrm{~nm}$, wavelength accuracy of $\pm 0.5 \mathrm{~nm}$ and wavelength reproducibility of $\pm 0.02 \mathrm{~nm}$ was utilized for the analysis. Raman spectra were measured at room temperature using a confocal Raman microscope (WITec, Alpha $300 \mathrm{R}$ ) with a $632.8 \mathrm{~nm}$ He-Ne laser. Electrical conductivity measurements were performed using standard four-in-line probe apparatus. The thickness of polymer thin films was measured by an Alpha-Step profilometer. An XE-100 atomic force microscopy (AFM) Park system, Korea, was used for the characterization. High-resolution X-ray photoelectron spectroscopy (XPS) experiments were performed on the PLS-8A1 undulator (U7) beam line equipped with a variable-included-angle planegrating monochromator, Japan. Cyclic voltammograms (CV) were from $\mathrm{CH}$ Instruments, USA. Cathodoluminescence (CL) experiments were carried out using a MonoCL3 purchased from Gaton (UK). The film thicknesses of PHVTT films used for the electrical conductivity, AFM, XPS, Raman spectra and CL measurements were $39 \mu \mathrm{m}$.

\subsection{APPJ device}

The key components of the soft plasma jet system are electrodes, dielectrics, and a high-voltage power supply., ${ }^{6,7}$ The AC power supply is a commercially available neon light transformer operating at $60 \mathrm{~Hz}$ and is connected to two electrodes. The primary voltage of the high-voltage transformer is regulated with the help of a voltage controller. The inner electrode is a typical injection needle made of stainless steel having an inner diameter of $1.2 \mathrm{~mm}$ with a thickness of $0.2 \mathrm{~mm}$; it is tightly covered with a quartz tube having an outer diameter of $3.2 \mathrm{~mm}$. The quartz tube is inserted through the inner electrode which is machined using porous alumina $10 \mathrm{~mm}$ in diameter and $20 \mathrm{~mm}$ in length. The tip of the inner electrode is placed in contact with the inner surface of the porous alumina. The outer electrode with a conical shape is fabricated from stainless steel, and the plasma jet is ejected to the surrounding ambient air through a centrally perforated hole of $1 \mathrm{~mm}$. The porous alumina with the inner electrode is installed within the outer electrode. The distance between the tips of the porous alumina and the inner electrode is referred to as the discharge gap ( $\mathrm{dg}$; in this work, $\mathrm{dg}$ is $2 \mathrm{~mm}$ ) which could be adjusted by controlling the depth at which the inner electrode was inserted into the porous alumina. The inner surface of the outer electrode is also in contact with the tip of the porous alumina. Air is injected into the injection needle through a $1 \mathrm{~mm}$ hole in the outer electrode via the porous alumina. The alumina used for the inner electrode had approximately $30 \% \mathrm{vol}$. porosity with an average pore diameter of $100 \mu \mathrm{m}$. Once air is introduced through the inner electrode and high-voltage AC power is applied, a discharge is fired in the porous alumina between the electrodes, generating a long plasma jet reaching up to several centimeters in length which is ejected into the open air. Compressed atmospheric dry air, Ar and $\mathrm{N}_{2}$ gas with a purity of $99.9999 \%$ were used at a flow rate of 1 liter $\mathrm{min}^{-1}$, which can be adjusted and measured by a mass flow controller.

We can determine the plasma parameters of electron temperature using a high-speed image-intensifying camera which can record the temporal propagation distance versus elapsed time. Recording the average value of temporal distance $\Delta x$ versus time interval $\Delta t$ can help in obtaining the average plasma propagation speed for the ionization front as $v=\frac{\Delta x}{\Delta t}=0.7 \mathrm{~cm} \mathrm{\mu s}^{-1}$. This plasma speed can then be expressed by the relation $v=\sqrt{\frac{k T_{\mathrm{e}}}{M}}$. Here the electron temperature $k T_{\mathrm{e}}$ can be experimentally measured as $\sim 1.7 \mathrm{eV}$ under different gases. Also the plasma density can be calculated from $n_{\mathrm{e}}=\frac{I(t)}{2 \pi e v \sigma^{2}} \exp \left(\frac{-r^{2}}{2 \sigma^{2}}\right)$ where $I$ is measured electric current, $e$ is the electron charge, $v=\sqrt{\frac{k T_{\mathrm{e}}}{M}} \sim$

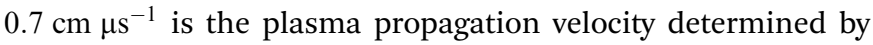
high speed image camera, and $\sigma$ is a radial profile of the plasma jet determined by experiment. The electron temperature is $\approx 0.8-1.0 \mathrm{eV}$ and plasma density is $2.0 \times 10^{13} \mathrm{~cm}^{-3}$ in this experiment, using the atmospheric pressure collisional radiative model and ion collector current. The emission spectrum of $\mathrm{N}_{2}$ gas plasma is shown in Fig. 1, whereas the air and Ar gas plasma emission spectra are illustrated in Fig. S1 and S2 (ESI $\dagger$ ).

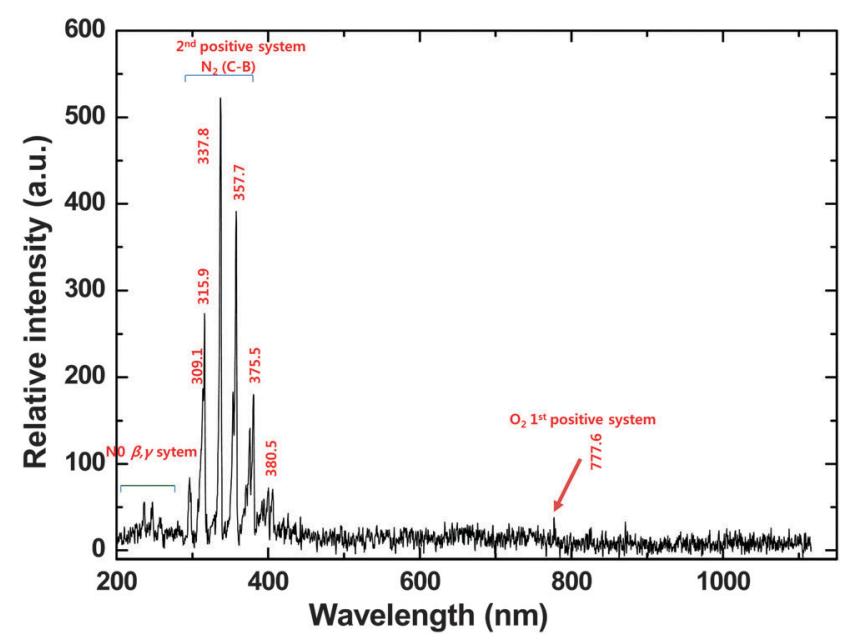

Fig. 1 The emission spectrum of atmospheric-pressure plasma jet (APPJ) with $\mathrm{N}_{2}$ as feeding gas. 
It was observed in this experiment that the VUV lines in the range 120-200 $\mathrm{nm}$ were easily absorbed by the atmospheric oxygen molecules. However, the emission lines beyond $200 \mathrm{~nm}$ easily passed through the oxygen molecules in the atmospheric air, which enabled us to explore the emission spectrum in the wavelength range of 200-1000 nm. Emission lines were observed for the molecular NO $\beta, \gamma$ system between 200 and $250 \mathrm{~nm}$ and superoxide anion $\mathrm{O}_{2}{ }^{*}$ at $245 \mathrm{~nm}$ as well as the emission line of $309.1 \mathrm{~nm}$ appearing for $\mathrm{OH}$ radicals in the case of all the feeding gas plasmas. We noticed that the emission spectra for the molecular $\mathrm{N}_{2}(\mathrm{C}-\mathrm{B})$ second positive system for all air, $\mathrm{N}_{2}$ and Ar feeding gas plasmas were concentrated in the wavelength range of 300$400 \mathrm{~nm}$, whereas the emission spectra for molecular $\mathrm{N}_{2}^{+}(\mathrm{B}-\mathrm{X})$ were seen as spectrum lines in the wavelength range of $450-600 \mathrm{~nm}$, and those for $\mathrm{N}_{2}(\mathrm{~B}-\mathrm{A})$ were observed in the wavelength range of 600-700 nm, in the case of the air gas plasma only. Also, the emission lines for the $\mathrm{O}_{2}$ first negative system were observed in the wavelength range of 470-620 nm, whereas typical $500.6 \mathrm{~nm}$ was a characteristic line in the case of the air gas plasma experiment. Also, the lines of the $\mathrm{N}_{2}$ molecular first positive system appeared in the range of 700-900 $\mathrm{nm}$ in the case of the air plasma only. It is necessary to mention that the oxygen atom $\mathrm{O}$ lines appearing at $777.6 \mathrm{~nm}$ were observed in the cases of all feeding gas plasmas, while the peak at $844.8 \mathrm{~nm}$ for O lines was evident only in the case of air and Ar gas feeding plasmas.

\subsection{Work function and secondary electron emission coefficient of polymer and modified polymer using $\gamma$-focused ion beam $(\gamma$-FIB) system}

In order to examine the changes in the secondary electron emission coefficient $(\gamma)$ and molecular energy band structure of the polymer due to atmospheric nonthermal plasma treatment, we used a $\gamma$-focused ion beam $\left(\gamma\right.$-FIB) system in this experiment. ${ }^{8,27}$ Fig. S3 (ESI $\dagger$ ) shows a schematic view of the $\gamma$-FIB consisting of the ionization region of ions, thermal electron source, electrostatic single Einzel lens that focuses on the ion beam, and collector and copper pad for secondary electron emission measurements from the surface of the polymer thin films. We used $\mathrm{He}^{+}$ions whose ionization energy $E_{\mathrm{i}}$ is $24.58 \mathrm{eV}$, with low energy below $200 \mathrm{eV}$. The $\mathrm{He}^{+}$ions approach the surface of the polymer film. The electric field is polarized toward the collector from the grounded copper pad when the collector potential is negatively biased. The secondary electrons emitted from the surface by these slow ions then come back, and only the ion current $\left(I_{\mathrm{i}}\right)$ coming to the surface is then measured. On the other hand, a positively biased collector makes the electric field toward the grounded copper pad. Due to this electric field, the secondary electrons emitted from the surface of the thin polymer film by the ion beam bombardment move up towards the collector, registering a current $\left(I_{\mathrm{t}}\right)$ in the ampere meter, in which the emitted secondary electron and ion beam currents $\left(I_{\mathrm{i}}\right)$ are included together. The secondary electron emission $\gamma$ is obtained from $\gamma=\left(I_{\mathrm{t}}-I_{\mathrm{i}}\right) / I_{\mathrm{i}}$.

\subsection{Fabrication of polymer solar cell devices}

The PSCs were fabricated based on the configuration ITO/ PEDOT:PSS/PHVTT:PC ${ }_{71} \mathrm{BM} / \mathrm{Al}$ via the following procedure.
ITO-coated glass substrates were thoroughly cleaned with a detergent, followed by treatment in an ultrasonic bath using different solvents in sequence: acetone, trichloroethylene and isopropanol. The cleaned substrates were then annealed at $150{ }^{\circ} \mathrm{C}$ in a vacuum oven for $20 \mathrm{~min}$ and subsequently exposed to UV ozone cleaning for 10-15 min. PEDOT:PSS (Sigma-Aldrich, USA, $1.3 \%$ dispersion in water) was spin-coated over the dried substrates using a digital spin coater with optimized spin for $\sim 40 \mathrm{~nm}$ film thickness. After this, the substrates were dried at $140{ }^{\circ} \mathrm{C}$ for $30 \mathrm{~min}$ in a vacuum oven and then transferred into a glove box for deposition of the active layer on the substrate using the spin-cast technique. Polymer and $\mathrm{PC}_{71} \mathrm{BM}\left(\mathrm{PC}_{71} \mathrm{BM}\right.$ from Sigma-Aldrich, USA) were separately dissolved in chlorobenzene $\left(20 \mathrm{mg} \mathrm{ml}^{-1}\right)$, followed by mixing of the two solutions. This mixture of PHVTT and $\mathrm{PC}_{71} \mathrm{BM}$ was used to develop active layers of the device in a ratio of $1: 1.5$. The film thicknesses of PHVTT: $\mathrm{PC}_{71} \mathrm{BM}$ in various devices were between 130 and $150 \mathrm{~nm}$ as measured by a stylus profilometer (Ambios XP200 Profiler). The active layer was spin-cast on the PEDOT:PSS film and cured at $140{ }^{\circ} \mathrm{C}$ for 20 min under nitrogen atmosphere in a glove box. Finally, aluminium electrodes of thickness of $120 \mathrm{~nm}$ were deposited through a shadow mask inside the thermal evaporator chamber having vacuum $\sim 8 \times 10^{-6}$ mbar. The active area of the pixel device prepared was $\sim 0.075 \mathrm{~cm}^{2}$. The current density-voltage $(J-V)$ characteristics of the devices were recorded using a Keithley 2420 Source Meter unit interfaced with a computer, performed under a tungsten halogen lamp with illumination intensity of $1000 \mathrm{~W} \mathrm{~m}^{-2}$ with 1.5 air mass (AM 1.5G). The device performance was measured by the efficiency $(\eta)$ and fill factor (FF). For each type of device, 5 specimens were fabricated with 4 pixels each and results are presented as the average of all 20 pixels. The efficiency of the solar cell is calculated as $\eta=\frac{V_{\max } \times J_{\max }}{1000}$. Here $V_{\max }$ and $J_{\max }$ are, respectively, the maximum voltage and maximum current drawn from the device. The FF is measured by $\mathrm{FF}=\frac{\eta}{V_{\mathrm{oc}} \times J_{\mathrm{sc}}}$. Here $V_{\mathrm{oc}}$ is the open circuit voltage and $J_{\mathrm{sc}}$ is the short circuit current. However, variation in the device performance may be due to variation in the film thickness of hole transport layers and active layers as the spin-coating process of the respective materials can only produce film thicknesses in a range of values. ${ }^{28}$

\section{Results and discussion}

Recent development of low bandgap polymers allows the energylevel engineering of polymers for enhancing photovoltaic performance. ${ }^{29-31}$ Hence, we synthesized and characterized the low bandgap PHVTT polymer as per our previously reported work. ${ }^{26}$ The UV-visible absorption spectra of PHVTT (Fig. 2a) show the absorption onset of PHVTT polymer at $750 \mathrm{~nm}$, indicating an optical bandgap. Therefore, we studied the bulk heterojunction photovoltaic cells, fabricated on the basis of ITO/PEDOT:PSS/ PHVTT:PC ${ }_{71} \mathrm{BM} / \mathrm{LiF} / \mathrm{Al}$ configuration, and measured their performances under $100 \mathrm{~mW} \mathrm{~cm}{ }^{-2}$. $\mathrm{PC}_{71} \mathrm{BM}$ was preferred over $\mathrm{PC}_{61} \mathrm{BM}$ due to its stronger light absorption in the visible region. ${ }^{23}$ 

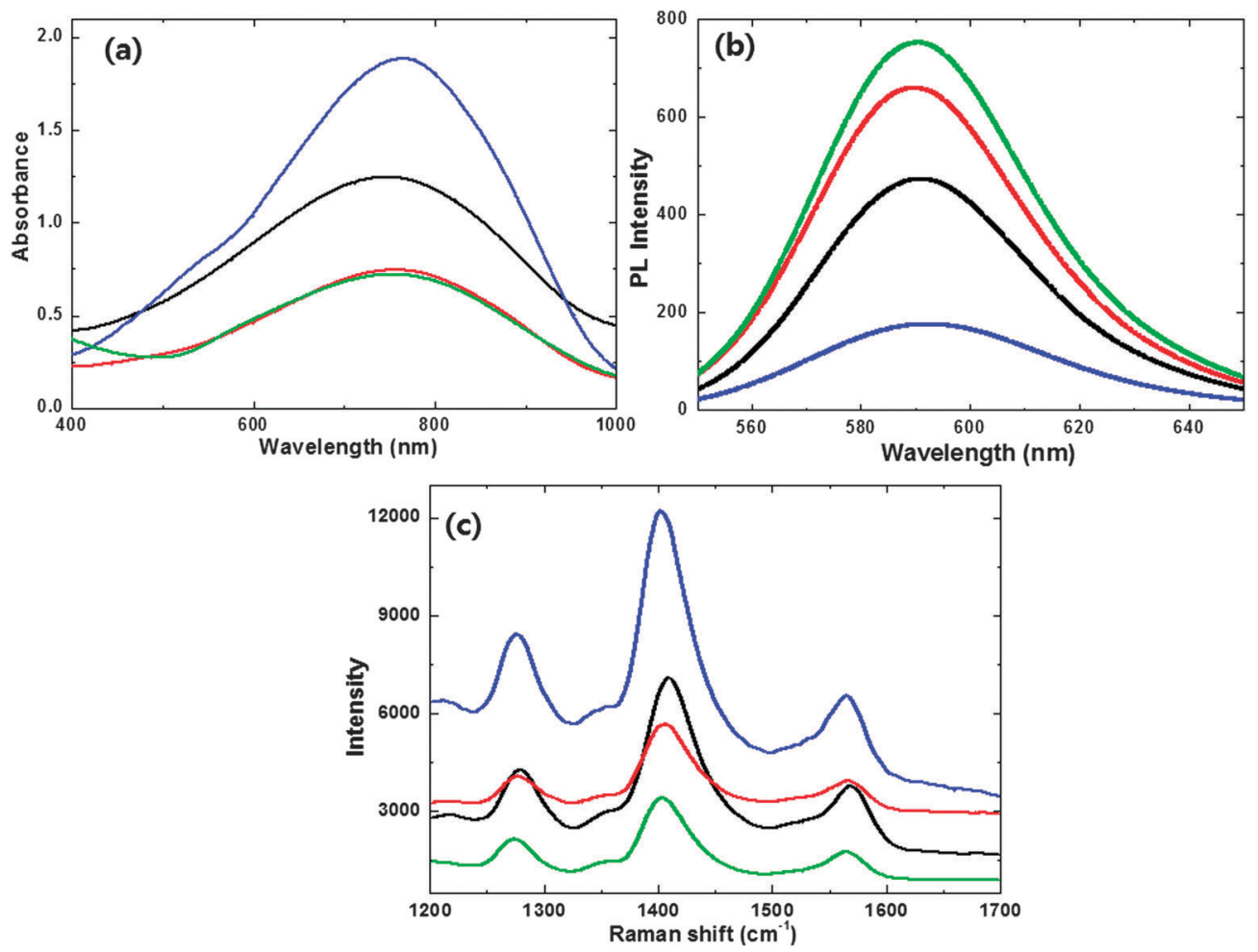

Fig. 2 (a) UV-visible absorption spectra, (b) photoluminescence (PL) spectra and (c) confocal Raman spectra of polymer (black), polymer treated with air plasma (red), polymer treated with $\mathrm{N}_{2}$ plasma (blue) and polymer treated with Ar plasma (green).

Table 1 Photovoltaic and electrochemical properties of the PHVTT(1):PC ${ }_{71} \mathrm{BM}(1.5)$ devices

\begin{tabular}{|c|c|c|c|c|c|c|c|c|c|}
\hline Device & HOMO $(\mathrm{eV})$ & LUMO (eV) & $E_{\mathrm{g}}(\mathrm{eV})$ & $V_{\mathrm{oc}}(\mathrm{V})$ & $J_{\mathrm{sc}}\left(\mathrm{mA} \mathrm{cm}^{-2}\right)$ & $\mathrm{FF}(\%)$ & $R_{\mathrm{SH}}\left(\times 10^{3} \Omega\right)$ & $R_{\mathrm{SR}}(\Omega)$ & PCE (\%) \\
\hline Air plasma & -4.77 & -3.57 & 1.20 & 0.75 & 10.93 & 58.45 & 165 & 846 & $4.87( \pm 0.05)$ \\
\hline
\end{tabular}

The devices based on PHVTT exhibit an efficiency of OPVs of 4.11\%, as shown in Table 1. This is still less than the reported efficiency of many OPVs ${ }^{29-31}$ and hence the synthesis of another new polymer using trial-and-error methods is not a good idea from the aspect of green chemistry. Therefore, we have used an APPJ operating with different feeding gases (air, $\mathrm{N}_{2}$ and Ar) to modify the synthesized low bandgap polymer in order to enhance the efficiency of OPVs.

\subsection{Characterization of modified polymer using UV-visible spectroscopy}

The energy of particles and the depth of impact created by APPJ are the important parameters for polymer surface modifications. The chemical bonds on the polymer surface can be disrupted after the impact of an energetic particle resulting in a more reactive surface. Thus, new reactive functional groups can be created and the polymer surface can be modified up to a depth of a few hundreds or thousands of angstroms. ${ }^{32}$ UV-visible spectroscopy provides substantial experimental results of the molecular modification of the polymer. After the treatment of the polymer with APPJ operating with different gases, the polymer spectrum exhibited a significant shift as compared to that of the control polymer (as displayed in Fig. 2a). The polymer showed a maximum absorption at $750 \mathrm{~nm}$, while PHVTT + air plasma showed a maximum absorption at $764 \mathrm{~nm}$ with an intensity reduction. This shows that the air plasma strongly modifies the low bandgap polymer. On the other hand, in the case of the polymer + Ar plasma a red shift with maximum absorption at $765 \mathrm{~nm}$ was observed, with an intensity reduction slightly more than in the case of PHVTT + air plasma. The combination of $\mathrm{N}_{2}$ plasma with the polymer also exhibited a red shift with a more intense maximum absorption at $767 \mathrm{~nm}$. Thus, UV-visible spectroscopy results reveal that all the feeding gases of APPJ favorably modify the polymer surface.

\subsection{Characterization of polymer and modified polymer using photoluminescence (PL) spectroscopy, confocal Raman spectroscopy and $\mathrm{CV}$ measurements}

In order to gain more insight into the optical properties of the control polymer and plasma-modified polymer (polymer + plasma), we utilized PL spectroscopy, and the results are displayed in Fig. 2b. Maximum PL for the control polymer (without plasma treatment) 
was observed at $\approx 590 \mathrm{~nm}$, while the PHVTT + air plasma showed maximum PL at $589 \mathrm{~nm}$ with an enhanced intensity. This shows that, after air plasma treatment, the polymer showed a slightly blue wavelength shift, with increased intensity. On the other hand, there is no wavelength shift for polymer + Ar plasma as compared to polymer + air plasma, although the intensity of the peak increased more in the case of the Ar plasma-treated polymer. However, the $\mathrm{N}_{2}$ plasma-treated polymer exhibited a red shift of $3 \mathrm{~nm}$ with intensity reduction as compared to the control polymer. Thus, PL spectroscopy results reveal that $\mathrm{N}_{2}$ plasma treatment modified the PL spectra of the polymer to a greater extent as compared to plasma operating with the other feeding gases. To further investigate the modification of the low bandgap polymer, we made use of the confocal Raman spectroscopy.

In order to elucidate the modification of the polymer, we employed another reliable technique, confocal Raman spectroscopy, that allowed us to take advantage of the spatial resolution of the confocal microscope. ${ }^{33,34}$ From Fig. 2c, we found that the polymer showed significant peaks at 1278, 1410 and $1568 \mathrm{~cm}^{-1}$, while for the plasma-treated polymer we observed a blue shift that confirmed the modification of the polymer using APPJ. In the case of polymer + air plasma, we found broad Raman peaks at 1274, 1405 and $1566 \mathrm{~cm}^{-1}$ as compared to the control polymer, although wavelength shifts and quenched intensity were also observed in the spectrum of the air plasma-treated polymer at 1273, 1401 and $1564 \mathrm{~cm}^{-1}$. On the other hand, sharp and highly intense peaks were detected for the $\mathrm{N}_{2}$ plasma-treated polymer at 1274,1400 and $1565 \mathrm{~cm}^{-1}$. Hence, variation in wavelength shift, broadening and intensity of peaks in Raman spectra after plasma treatment revealed modification of the polymer to different extents using plasma operating with different feeding gases.

Additionally, CV was employed to examine the electrochemical properties and evaluate the HOMO and LUMO levels of the polymers. The results are shown in Table 1 and Fig. S4 $(\mathrm{ESI} \dagger)$. The onset oxidation potentials $\left(E_{\mathrm{ox}}\right)_{\text {on }}$ for the polymer, polymer + air plasma, polymer $+\mathrm{N}_{2}$ plasma and polymer $+\mathrm{Ar}$ plasma are $0.363 \mathrm{eV}, 0.379 \mathrm{eV}, 0.478 \mathrm{eV}$ and $0.383 \mathrm{eV}$, whereas the onset reduction potentials $\left(E_{\mathrm{red}}\right)_{\text {on }}$ for the polymer, polymer + air plasma, polymer $+\mathrm{N}_{2}$ plasma and polymer + Ar plasma are $-0.767 \mathrm{eV},-0.826 \mathrm{eV},-0.771 \mathrm{eV}$ and $-0.827 \mathrm{eV}$. These values for $\left(E_{\text {ox }}\right)_{\text {on }}$ and $\left(E_{\text {red }}\right)_{\text {on }}$ are correlated linearly with HOMO and LUMO energy with a correction factor of $4.4 \mathrm{eV}$. The HOMO and LUMO values deduced from CV measurements for the polymer and treated polymer are reported in Table 1. The HOMO energy levels of control polymer and polymer $+\mathrm{N}_{2}$ plasma were found to be between -4.763 and $-4.878 \mathrm{eV}$, whereas the LUMO energy levels of control polymer and polymer $+\mathrm{N}_{2}$ plasma were found to be between -3.633 and $-3.629 \mathrm{eV}$ with a small variation, which shows that both HOMO and LUMO levels were modified to an appreciable extent using APPJ. Apparently, the more powerful the acceptor, the higher the electron affinity, which finally leads to lower-lying LUMO level in these polymers, although on treating the polymer with plasma, we can modify its bandgap and increase its utility to a larger extent. To further investigate the surface properties of the polymer, we continued with conductivity measurements and AFM.

\subsection{Conductivity and surface roughness measurements of polymer and modified polymer}

Nowadays, the improvement in the conductivity of polymers is a very important issue. There are numerous ways to enhance the conductivity of polymers by adding secondary dopants or additives such as several alcohols and high-boiling-point solvents. ${ }^{35,36}$ Still, these methodologies suffer from many limitations, so we tried to enhance the conductivity by utilizing a plasma in the work reported here. Our experimental conductivity results displayed in Table 2 show that the conductivity of the polymer is $7.0 \times 10^{-5} \mathrm{~S} \mathrm{~cm}^{-1}$ at $25{ }^{\circ} \mathrm{C}$, whereas after plasma treatment, the conductivity of the polymer increased. After treating the polymer with plasma operating with air, Ar and $\mathrm{N}_{2}$ gases, the conductivity of the polymer was found to be $3.1 \times 10^{-4}, 3.3 \times$ $10^{-3}$ and $6.3 \times 10^{-3} \mathrm{~S} \mathrm{~cm}^{-1}$, respectively. The $\mathrm{N}_{2}$ plasmatreated polymer had maximum conductivity, whereas the air plasma-treated polymer had minimum conductivity. In any case, the plasma-treated polymer irrespective of feeding gases had a greater conductivity than the control polymer. Therefore, we concluded that the conductivity of polymer increased to a greater extent on plasma treatment.

To gain insight into the conductivity enhancement of the polymer after treatment with APPJ operating with different feeding gases, we investigated the surface morphology of control polymer and plasma-modified polymer using AFM. The modification of PHVTT polymer with plasma treatment resulted in a decrease of average surface roughness. The surface morphology of polymer and plasma-modified polymer is shown in Fig. 3. It is obvious that PHVTT (control polymer) exhibits more surface roughness in comparison to the modified polymer surface. During plasma treatment, ablation of the polymer surface takes place with a different ablation rate of amorphous and crystalline phases that resulted in the appearance of the amorphous structures on the plasma-modified polymer surface. The control polymer showed an average roughness $\left(R_{\mathrm{a}}\right)$ of about $38.048 \mathrm{~nm}$, while after air plasma treatment $R_{\mathrm{a}}=9.830 \mathrm{~nm}$. This reveals that the plasma treatment of the polymer surface makes it smoother. After the Ar plasma treatment, $R_{\mathrm{a}}$ of the polymer comes out to be $9.236 \mathrm{~nm}$, again suggesting that Ar plasma treatment makes the polymer surface smoother than air plasma treatment, whereas $R_{\mathrm{a}}=8.820 \mathrm{~nm}$ for the $\mathrm{N}_{2}$ plasma-treated polymer reveals that this treatment has greater tendency to smoothen and minimize the roughness of the polymer as compared to plasma operating with other feeding gases. This could be the important factor for

Table 2 Conductivity of polymer and polymer treated with plasma in different feeding gases

\begin{tabular}{ll}
\hline Sample & Conductivity $\left( \pm 0.4 \mathrm{~S} \mathrm{~cm}^{-1}\right)$ \\
\hline Polymer & $7.0 \times 10^{-5}$ \\
Polymer + air & $3.0 \times 10^{-4}$ \\
Polymer $+\mathrm{N}_{2}$ & $6.0 \times 10^{-3}$ \\
Polymer $+\mathrm{Ar}$ & $3.0 \times 10^{-3}$
\end{tabular}


(a)

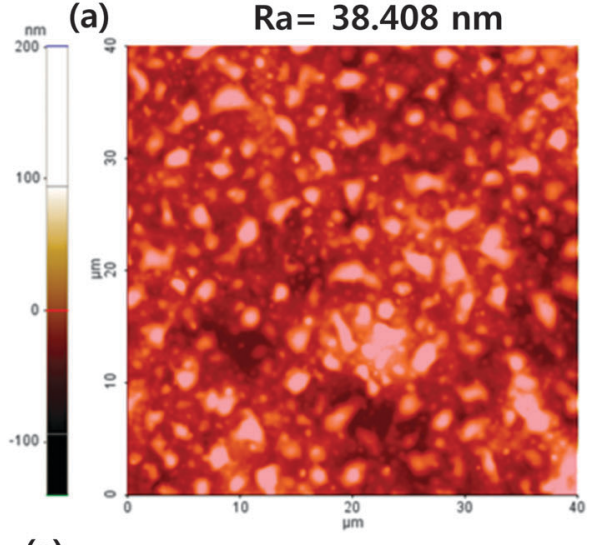

(c)

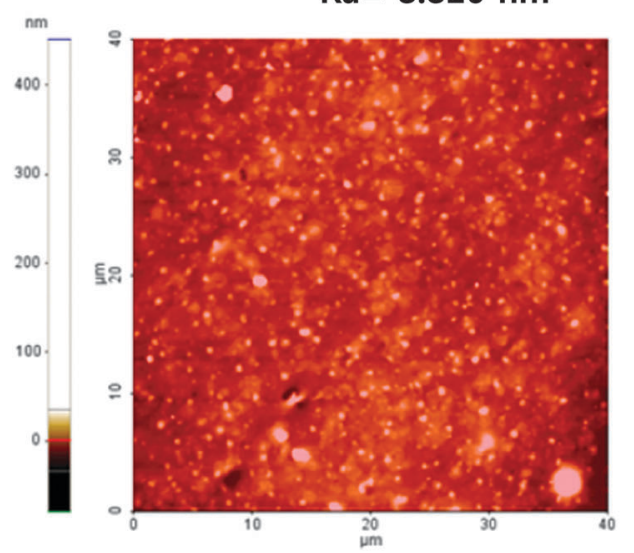

(b)

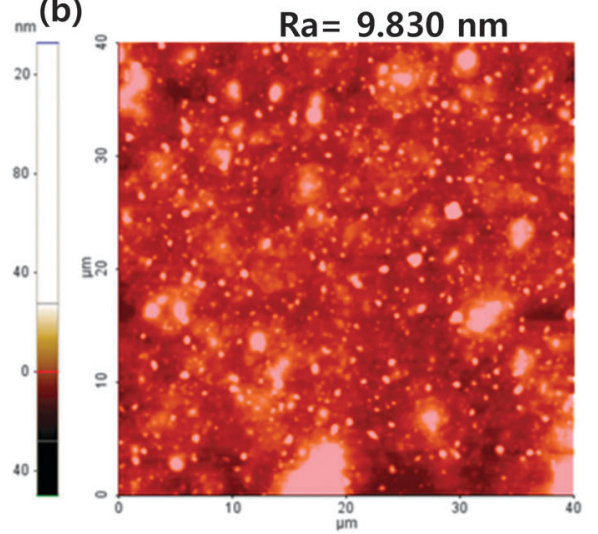

(d)

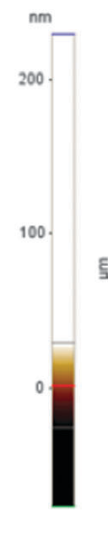

$\mathrm{Ra}=9.236 \mathrm{~nm}$

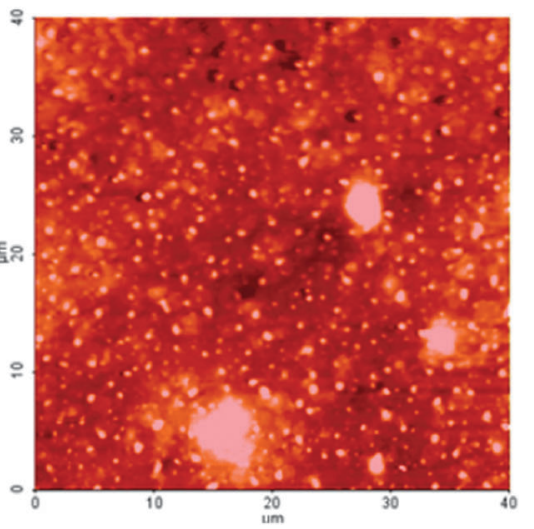

Fig. 3 AFM images of thin films cast from (a) polymer, (b) polymer treated with air plasma, (c) polymer treated with $\mathrm{N}_{2}$ plasma and (d) polymer treated with Ar plasma. The scan size for all images is $40 \mathrm{~mm} \times 40 \mathrm{~mm}$.

enhancing the conductivity of the polymer after the $\mathrm{N}_{2}$ plasma treatment.

\subsection{Characterization of polymer and modified polymer surface using X-ray photoelectron spectroscopy}

The influence of plasma treatment on the polymer surface was studied using XPS. The PHVTT samples modified by APPJ plasma operating with the different feeding gases were analyzed. The results from XPS measurements are summarized in Fig. S5 to S8 (ESI $\dagger$ ). The chemical structure of PHVTT consists of carbon, sulfur and nitrogen in the basic polymer chain, while after plasma treatment, we observed the generation of oxygen that results in the structural changes or oxidation of the polymer. The control polymer has no oxygen in its structure; therefore, the changes in oxygen concentration after plasma treatment can be traced successfully. Further, all peaks of control polymer and modified polymer were examined using the previous literature, and are provided in Fig. S5 to S8 (ESI $\dagger)^{37-44}$

The C 1s core level spectrum of the control polymer is illustrated as Fig. S5 (ESI $\dagger$ ). The binding energies were corrected by taking the $\mathrm{C} 1 \mathrm{~s}$ core level at $284.6 \mathrm{eV}$ for all samples. ${ }^{45,46}$ The peaks at 284.2, 285.7, 286.7, and $290.1 \mathrm{eV}$ correspond to $\mathrm{C}-\mathrm{C}$, $\mathrm{C}-\mathrm{S}, \mathrm{C}=\mathrm{N}$ groups of the polymer and the $\pi \rightarrow \pi^{*}$ shake up signals from the thiophene ring, respectively. The $\mathrm{C} 1 \mathrm{~s}$ spectrum of the modified polymer after air plasma treatment revealed peaks at 284.2, 286.2 and $287.6 \mathrm{eV}$ corresponding to $\mathrm{C}-\mathrm{C}, \mathrm{C}=\mathrm{N}$ and $\mathrm{C}=\mathrm{O}$ groups, respectively. Thus, the addition of oxygen in the air plasma as compared to the control polymer resulted in the modification of the polymer surface, whereas in the case of Ar plasma-treated polymer, we detected peaks at 284.2, 285.9 and $287.2 \mathrm{eV}$ corresponding to $\mathrm{C}-\mathrm{C}, \mathrm{C}-\mathrm{O}$ and $\mathrm{C}=\mathrm{O}$ groups, respectively, the $\mathrm{C}=\mathrm{N}$ being replaced with $\mathrm{C}-\mathrm{O}$ group after the $\mathrm{Ar}$ gas plasma treatment. On the other hand, after $\mathrm{N}_{2}$ plasma treatment of the polymer, we observed peaks at 284.2 and $285.9 \mathrm{eV}$ that correspond to $\mathrm{C}-\mathrm{C}$ and $\mathrm{C}-\mathrm{O}$ of the modified polymer, respectively. Here, the peak appearing at $287 \mathrm{eV}$ in the case of all other plasma treatments is absent and thus it suggests that the $\mathrm{N}_{2}$ plasma modifies the polymer to a greater extent.

Similarly, O 1s core level spectra are illustrated in Fig. S6 (ESI $\dagger$ ) which shows that $\mathrm{O} 1 \mathrm{~s}$ is absent, because of the absence of oxygen moiety in the polymer, whereas the oxygen peak appeared in the spectra of the plasma-treated polymer samples. The $\mathrm{O} 1 \mathrm{~s}$ spectrum of the air plasma-modified polymer revealed peaks at 531.0, 532.1, 532.8 and $534.1 \mathrm{eV}$ corresponding to $\mathrm{O}=\mathrm{C}-\mathrm{N}, \mathrm{O}=\mathrm{C}-\mathrm{O}, \mathrm{C}-\mathrm{O}-\mathrm{C}$ or $\mathrm{C}-\mathrm{O}-\mathrm{H}$, and $\mathrm{O}=\mathrm{C}-\mathrm{O}-\mathrm{C}$ groups, respectively, whereas after Ar plasma treatment, we observed peaks for modified polymer at 531.1, 532.2 and 534.1 eV corresponding to $\mathrm{O}=\mathrm{C}-\mathrm{N}, \mathrm{O}=\mathrm{C}-\mathrm{O}$, and $\mathrm{O}=\mathrm{C}-\mathrm{O}-\mathrm{C}$ groups, respectively. The peaks corresponding to $\mathrm{C}-\mathrm{O}-\mathrm{C}$ or $\mathrm{C}-\mathrm{O}-\mathrm{H}$ groups were absent in this case as compared with air plasma-treated polymer. 
Further, in the case of $\mathrm{N}_{2}$ plasma-treated polymer, we observed peaks at 531.2 and $532.9 \mathrm{eV}$ which again corresponded to $\mathrm{O}=\mathrm{C}-\mathrm{N}$ and $\mathrm{C}-\mathrm{O}-\mathrm{C}$ or $\mathrm{C}-\mathrm{O}-\mathrm{H}$ groups, respectively. The peaks at 532.1 and $534.1 \mathrm{eV}$ were present in the case of other feeding gas plasma source treatment of the polymer, but these were found to be absent in the case of the $\mathrm{N}_{2}$ plasma-treated polymer. This again suggests that the $\mathrm{N}_{2}$ plasma modified the polymer to a greater extent and selectivity of the polymer increases by changing the feeding gases in APPJ.

The $\mathrm{N}$ 1s core level spectrum is illustrated as Fig. S7 (ESI $\dagger$ ). The $\mathrm{N}$ 1s core level spectrum of the control polymer showed a peak at $399.9 \mathrm{eV}$ corresponding to $\mathrm{C}=\mathrm{N}$ group of the polymer. The $\mathrm{N}$ 1s spectrum of the polymer modified with air plasma treatment revealed peaks at 398.0, 402.1 and $405.2 \mathrm{eV}$, corresponding to $\mathrm{C}=\mathrm{N}, \mathrm{NH}_{2}{ }^{+}$and $\mathrm{NO}$ or $\mathrm{NO}_{2}$ groups of the polymer. Thus, the presence of oxygen in the polymer after the air plasma treatment as compared to the control polymer is due to the modification of the polymer surface by the plasma treatment, while for Ar plasma-treated polymer, we observed peaks at $397.1,403.1$ and $407.6 \mathrm{eV}$ corresponding to $\mathrm{C}=\mathrm{N}$, $\mathrm{NH}_{2}{ }^{+}$and $\mathrm{NO}$ or $\mathrm{NO}_{2}$ groups, respectively. Hence the results are similar to those for the air plasma-treated polymer, with a difference of more intense peaks in the case of the Ar plasmatreated polymer, whereas for the $\mathrm{N}_{2}$ plasma-treated polymer, we observed peaks at 397.9, 402.9 and $405.2 \mathrm{eV}$ corresponding to $\mathrm{C}=\mathrm{N}, \mathrm{NH}_{2}{ }^{+}$and $\mathrm{NO}$ groups, respectively. The peaks in all cases of the APPJ feeding gases are the same but the intensity of the peaks is less in the case of the $\mathrm{N}_{2}$ plasma-treated polymer as compared to the other plasma sources.

Typical S 2p spectra of the polymer before and after the plasma treatment are shown in Fig. S8 (ESI $\dagger$ ). The spectra showed two $\mathrm{S} 2 \mathrm{p}$ bands, each corresponding to a doublet of $\mathrm{S} 2 \mathrm{p}_{3 / 2}$ and $\mathrm{S} 2 \mathrm{p}_{1 / 2}$ components with spin-orbit splitting and having a $2: 1$ intensity ratio. The weaker $S 2 p_{3 / 2}$ peak at $163.9 \mathrm{eV}$ and the stronger $\mathrm{S} 2 \mathrm{p}_{3 / 2}$ peak at $167.1 \mathrm{eV}$ correspond to the sulfur atoms of the polymer, respectively. The S 2p spectrum of the air plasma-modified polymer revealed peaks at 161.1, 163.0, 163.9, 166.2 and $169.3 \mathrm{eV}$ corresponding to absorption by lone "S", C-S-C, S-H, and S-atom and oxidized sulfur of the polymer. Thus, the presence of oxygen in the air plasma resulted in the modification of the polymer surface, while the Ar plasma-treated polymer showed peaks at 162.9, 163.8 and $166.2 \mathrm{eV}$ corresponding to $\mathrm{C}-\mathrm{S}-\mathrm{C}, \mathrm{S}-\mathrm{H}$ groups and $\mathrm{S}$-atom respectively, with an absence of the oxidized sulfur peak. This also reveals that more oxidation of the polymer occurs in the presence of air plasma than Ar plasma, whereas for the $\mathrm{N}_{2}$ plasma-treated polymer, we detected peaks at 163.1, 164.0 and $166.3 \mathrm{eV}$ corresponding to $\mathrm{C}-\mathrm{S}-\mathrm{C}, \mathrm{S}-\mathrm{H}$ groups, and $\mathrm{S}$-atom respectively. Hence, use of $\mathrm{Ar}$ and $\mathrm{N}_{2}$ plasmas resulted in controlled modification of the polymer, whereas use of air plasma resulted in modification of the polymer to a greater extent, with the formation of oxidized sulfur. Hence, we can also predict the surface modification of the low bandgap polymer using XPS. In order to examine the bulk modification of the polymer, we have further measured the work function using $\gamma$-FIB and CL.

\subsection{Characterization of bulk modification of polymer using $\gamma$-FIB and CL}

The measurement of the work function of a polymer before and after APPJ treatment with different feeding gases is an important factor for determining the mechanism of the increase in conductivity of the polymer after plasma treatment. ${ }^{27}$ The work function was calculated using the $\gamma$-FIB system; the results are shown in Fig. 4a and Table 3. The work function of the control polymer was calculated to be $11.11 \mathrm{eV}$, whereas after the air plasma treatment the work function of the polymer was measured as $9.88 \mathrm{eV}$. Additionally, the work function of the polymer after the $\mathrm{Ar}$ and $\mathrm{N}_{2}$ plasma treatments was found to be 9.86 and
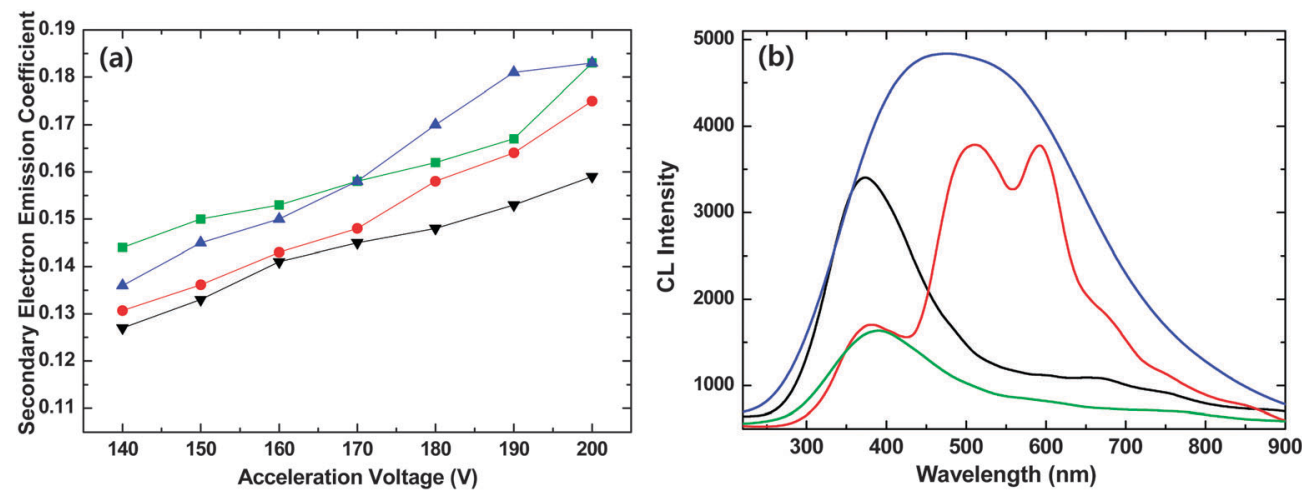

Fig. 4 (a) Secondary electron emission coefficient and (b) cathodoluminescence (CL) spectrum intensity of polymer (black), polymer treated with air plasma (red), polymer treated with $\mathrm{N}_{2}$ plasma (blue) and polymer treated with Ar plasma (green).

Table 3 Work function of polymer and polymer treated with plasma with different feeding gases

\begin{tabular}{lllll}
\hline & Control & Air & $\mathrm{N}_{2}$ & $\mathrm{Ar}$ \\
\hline Work function $(\mathrm{eV})$ & $11.11( \pm 0.006)$ & $9.88( \pm 0.007)$ & $9.56( \pm 0.004)$ & $9.86( \pm 0.005)$
\end{tabular}


9.56 eV, respectively. Therefore, we found that after the plasma treatment the work function decreases very fast as compared to that of the control polymer.

Subsequently, we studied the $\mathrm{CL}^{27}$ of the polymer both before and after the plasma treatment, as displayed in Fig. 4b. Here, similar results were obtained and were correlated with the above experimental data as maximum red shift and an increase in the intensity was observed for the $\mathrm{N}_{2}$ plasma-treated polymer. After air plasma treatment of the polymer, the red shift was seen with the appearance of an additional peak which suggests that there is formation of some sub-levels in the structure of the polymer after the air plasma treatment. Additionally, a reduction with a slight red shift was observed in the case of the Ar plasma-treated polymer. The observed difference in the spectra of control polymer and polymer after plasma treatment with different feeding gases could be due to the change in the crystal polymorphs of the polymer. Hence, CL data also support our results discussed above and suggest that there is a considerable change in the low bandgap polymer after plasma treatment, which in turn modifies its physical and optical properties to a greater extent.

\subsection{Increase in power conversion efficiency of bulk heterojunction solar cells}

Bulk heterojunction solar cells were fabricated with a sandwich structure of ITO/PEDOT:PSS/PHVTT:PC ${ }_{71} \mathrm{BM} / \mathrm{LiF} / \mathrm{Al}$. After deposition of the PEDOT:PSS layer on the top of the anode (ITO), the active materials were deposited via spin coating from 1,2-dichlorobenzene solution of PHVTT polymer and $\mathrm{PC}_{71} \mathrm{BM}$. The resulting films were dried under vacuum at room temperature for $4 \mathrm{~h}$, and then annealed at $90{ }^{\circ} \mathrm{C}$ for $10 \mathrm{~min}$ to remove the solvent. For the bulk heterojunction solar cells, the $\mathrm{PC}_{71} \mathrm{BM}$ was used as an electron acceptor and polymers were used as electron donor. The $J-V$ characteristics of the polymer solar cells prepared from the treated and untreated polymer: $\mathrm{PC}_{71} \mathrm{BM}$ blend materials are shown in Fig. 5. The short circuit current density $\left(J_{\mathrm{SC}}\right)$,

\section{ITO/PEDOT:PSS/PHVTT:PC ${ }_{71}$ BM/LiF/AI}

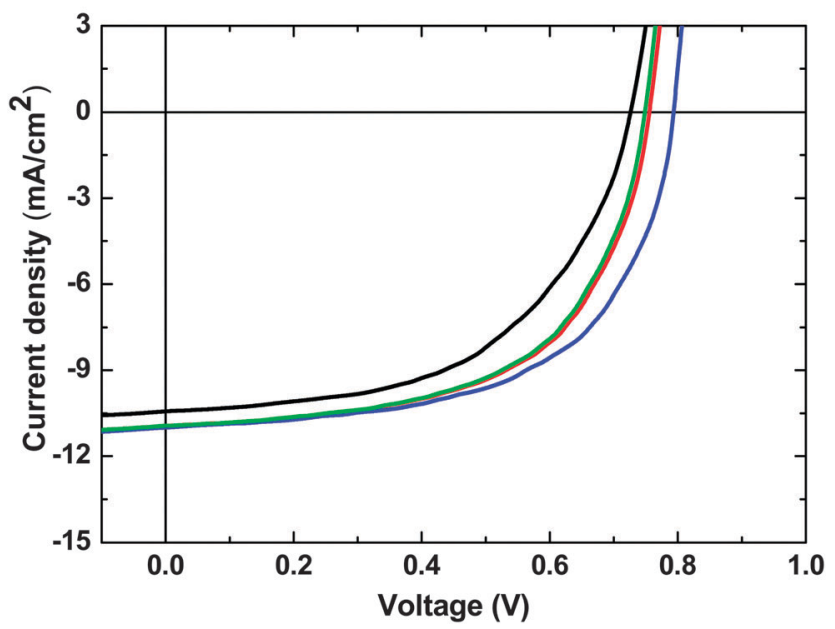

Fig. $5 \mathrm{~J}-\mathrm{V}$ characteristics of PSCs fabricated using polymer (black), polymer treated with air plasma (red), polymer treated with $\mathrm{N}_{2}$ plasma (blue) and polymer treated with Ar plasma (green). open circuit voltage $\left(V_{\mathrm{OC}}\right)$, fill factor $(\mathrm{FF})$, power conversion efficiency (PCE), series resistances $\left(R_{\mathrm{SR}}\right)$ and shunt resistance $\left(R_{\mathrm{SH}}\right)$ of these devices are summarized in Table 1 and Fig. 5. For these devices based on the PHVTT (with or without plasma treatment): $\mathrm{PC}_{71} \mathrm{BM}$ blend materials, an improvement in performance was observed for treated polymer as compared to control polymer. The PCEs of the control polymer and air, $\mathrm{Ar}$ and $\mathrm{N}_{2}$ plasma-treated polymer devices were found to be $4.11 \%, 4.83 \%$, $4.87 \%$ and $5.14 \%$, respectively. Although the polymer exhibited a low optical bandgap and broadest absorption spectrum, the low LUMO level hindered the efficient exciton dissociation, resulting in a low PCE of $4.11 \%$. These results are similar to those of Chen et al., where at lowest optical bandgap low PCE was observed and high PCE was observed at high bandgap. ${ }^{47}$ The polymer modified with the nitrogen plasma showed more red-shift, a broader absorption spectrum, high mobility, high bandgap and a higher PCE of 5.14\%. In view of this fact, the polymer modified with the nitrogen plasma showed a higher bandgap with intense absorption in the visible region. Although the air plasma- and Ar plasma-treated polymers also showed a red-shift, a broader absorption spectrum, high mobility, and a higher PCE of 4.83 and $4.87 \%$ respectively, these were less as compared to the $\mathrm{N}_{2}$ plasma-treated polymer. One of the reasons is that higher $V_{\mathrm{oc}}$ is obtained for the $\mathrm{N}_{2}$ plasma-treated polymer as compared to the other treated polymers. It is reported by Chen et al. ${ }^{48}$ that $V_{\text {oc }}$ in a low bandgap polymer is one of the critical factors towards higher PCE. Hence, plasma treatment not only changes the surface properties, but also modifies the bandgap between HOMO and LUMO (bulk properties) and also increases the PCE (as shown in Scheme 1 and Table 1).

To gain insight into the action of APPJ operating with different feeding gases on solid phase polymer, we further concentrated on the emission spectra as illustrated in Fig. 1, Fig. S1 and S2 (ESI $\dagger$ ). The spectra clearly elucidate the molecular NO $\beta, \gamma$ system, superoxide anion $\mathrm{O}_{2}{ }^{*}, \mathrm{OH}$ molecules and $\mathrm{N}_{2}$ (C-B) second positive system to be prominent for the $\mathrm{N}_{2}$ plasmatreated polymer, as compared to the case of Ar plasma- and air

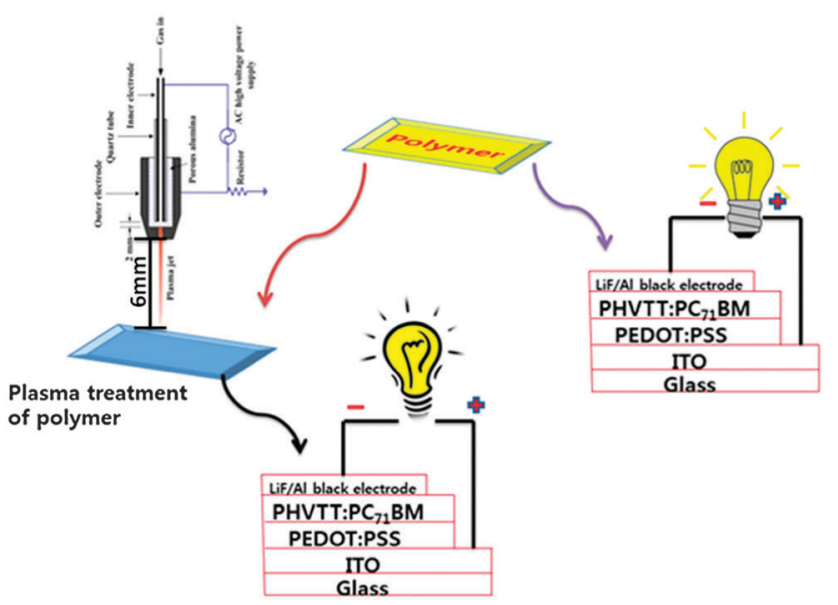

Scheme 1 Schematic diagram for the increase in power conversion efficiency (PCE) of the bulk heterojunction photovoltaic cells in the presence of the plasma-modified polymer. 
plasma-treated polymers. And, $\mathrm{N}_{2}^{+}(\mathrm{B}-\mathrm{X})$ and $\mathrm{N}_{2}(\mathrm{~B}-\mathrm{A})$ lines were found to be absent in the case of all plasmas except the air plasma. Moreover, intense emission lines from the $\mathrm{O}_{2}$ first negative system were observed for the air plasma- and $\mathrm{Ar}$ plasma-treated polymers, as compared to the $\mathrm{N}_{2}$ plasmatreated polymer. These different levels of radicals originating from the different feeding gases lead to different levels of modification. Plasma provides a reactive environment for the polymer surface. We observed that physical-chemical reaction occurred after plasma treatment that resulted in breaking of some chemical bonds, creation of some active sites near polar groups, modification of functional groups, etc. During this interaction of reactive species generated by plasma on polymer surfaces, reactions such as functionalization and intermolecular cross-linking occurred. Some of the reactions might be as follows:

$$
\begin{gathered}
\mathrm{R}-\mathrm{H} \rightarrow \mathrm{R}^{0}+\mathrm{H}^{0} \\
\mathrm{R}^{0}+\mathrm{O}_{2} \rightarrow \mathrm{ROO}^{0} \\
\mathrm{O}_{2} \rightarrow \mathrm{O}^{0}+\mathrm{O}^{0} \\
\mathrm{R}^{0}+\mathrm{O}^{0} \rightarrow \mathrm{R}^{0}+\mathrm{ROOH} \\
\mathrm{R}^{0}+\mathrm{O}^{0} \rightarrow \mathrm{ROOR} \\
\mathrm{ROOH}^{\rightarrow} \mathrm{RO}^{0}+\mathrm{OH}^{0} \\
\mathrm{RO}^{0}+\mathrm{H}^{0} \rightarrow \mathrm{ROH} \\
\mathrm{RO}^{0}+\mathrm{OH}^{0} \rightarrow \mathrm{ROOH}
\end{gathered}
$$

where $\mathrm{R}$ is an alkyl group. Many more reactions are possible that can modify the polymer. However, the VUV photons can generate various oxidation products such as $-\mathrm{C}-\mathrm{OH},-\mathrm{C}=\mathrm{O}$, $-\mathrm{C}-\mathrm{O}-\mathrm{C},-\mathrm{COOH}$ groups etc. ${ }^{49}$ Therefore, these are the main cause for the change in XPS peaks in the case of different feeding gas plasmas, resulting in the different extent of modification of the functional groups. Moreover, the changes in AFM topography measurements showed the smoothening of the polymer surface after the plasma treatment. This could possibly be due to the cross-linking of polymer bonds (mainly in amorphous phase) resulting in high mobility of radicals. These radicals are readily oxidized and preferential etching takes place in the amorphous region. ${ }^{49}$ This might again be the cause of changes in CL spectra after the plasma treatment of polymer. The plasma jet with air feeding gas showed a greater red shift in the CL spectra, as compared with the other feeding gases, due to the generation of more radicals in air plasma resulting in extensive cross-linking of the polymer. And this results in lower PCE of solar cell as compared with the polymer treated with the other feeding gas plasmas.

\section{Conclusion}

Our experimental data show that the structure of a polymer can be modified using plasma with different feeding gases. UV-visible spectroscopy results reveal that a red shift is observed for all plasma-treated polymers, which helps in harvesting more sunlight of longer wavelength. PL, CV, Raman spectroscopy and XPS experimental data indicated that physical and chemical properties of the polymer changed drastically after the plasma treatment. We also observed that the conductivity of the polymer increased after the plasma treatment with a decrease in roughness of the film after treatment. Likewise, PCE also increased after the treatment of the polymer with plasma. All these results led us to conclude that the maximum physical and chemical changes occurred in the $\mathrm{N}_{2}$ plasma-treated polymer due to presence of limited types of radicals, while the presence of more than one type of radicals in the air plasma increases the probability of converting reactive radical species to stable species. To summarize, all these radicals modify the polymer surface to different extents without destroying the polymer.

\section{Acknowledgements}

We gratefully acknowledge the National Research Foundation of Korea (NRF) grant funded by the Korea government (MSIP) (NRF-2010-0027963). This work was supported by the New \& Renewable Energy of the Korea Institute of Energy Technology Evaluation and Planning (KETEP) grant funded by the Korea government Ministry of Knowledge Economy (no. 96002011003) and by Ministry of Knowledge Economy (MKE), Korea, as a project, "Full color 360 degree 3D holographic video making technology" and by Ministry of Culture, Sports and Tourism (MCST) and Korea Creative Contents Agency (KOCCA) in the Culture Technology Research \& Development Program 2012 in part by Kwangwoon University 2014. JG and SC are thankful to DST, Government of India, for providing financial support under the India-UK joint initiative project entitled "Advancing the efficiency and production potential of excitonic solar cells (APEX)".

\section{References}

1 E. D. Kirson, V. Dbaly, F. Tovarys, J. Vymazal, J. F. Soustiel, A. Itzhaki, D. Mordechovich, S. Steinberg-Shapira, Z. Gurvich, R. Schneiderman, Y. Wasserman, M. Salzberg, B. Ryffel, D. Goldsher, E. Dekel and Y. Palti, Proc. Natl. Acad. Sci. U. S. A., 2007, 104, 10152-10157.

2 E. A. Ratovitski, X. Cheng, D. Yan, J. H. Sherman, J. Canady, B. Trink and M. Keidar, Plasma Process. Polym., 2014, DOI: 10.1002/ppap.201400071.

3 D. Staack, A. Fridman, A. Gutsol, Y. Gogotsi and G. Friedman, Angew. Chem., Int. Ed., 2008, 47, 8020-8024.

4 S. Ptasinska, B. Bahnev, A. Stypczynska, M. Bowden, N. J. Mason and N. S. Braithwaite, Phys. Chem. Chem. Phys., 2010, 28, 7779-7781.

5 G. Li, H.-P. Li, L.-Y. Wang, S. Wang, H.-X. Zhao, W.-T. Sun, X.-H. Xing and C.-Y. Bao, Appl. Phys. Lett., 2008, 92, 221504. 
6 P. Attri, P. Venkatesu, N. Kaushik and E. H. Choi, RSC Adv., 2012, 2, 7146-7155.

7 P. Attri and E. H. Choi, PLoS One, 2013, 8, e75096.

8 P. Attri, J. H. Park, J. Gaur, N. Kumar, D. H. Park, S. N. Jeon, B. S. Park, S. Chand, H. S. Uhm and E. H. Choi, Phys. Chem. Chem. Phys., 2014, 16, 18375-18382.

9 J. Julak, O. Janouskova, V. Scholtz and K. Holada, Plasma Processes Polym., 2011, 8, 316-323.

10 G. Bruno, P. Capezutto and A. Madan, Plasma Deposition of Amorphous Silicon-Based Materials, Academic Press, San Diego, 1995.

11 R. Wilhelm, Deposition properties and applications of carbon-based coatings, in Advanced Technologies Based on Wave and Beam Generated Plasmas, ed. H. Schluter and A. Shivarova, NATO Sci. Series, Kluwer, Dordrecht, 1999, vol. 67, pp. 123-135.

12 H. K. Yasuda, Plasma Polymerization and Plasma Interactions with Polymeric Materials, Wiley, New York, 1990.

13 Z. Ding, J. Chen, Sh. Gao, J. Chang, J. Zhang and E. T. Kang, Biomaterials, 2004, 25, 1059-1067.

14 K. Kim, C. Kim and Y. Byun, Biomaterials, 2004, 25, 33-41.

15 O. Goossens, E. Dekempeneer, D. Vangeneugden, R. Van de Leest and C. Leys, Surf. Coat. Technol., 2001, 142-144, 142-144.

16 J.-H. Kim, C. E. Song, I.-N. Kang, W. S. Shin and D.-H. Hwang, Chem. Commun., 2013, 49, 3248-3250.

17 L. Dou, J. You, J. Yang, C.-C. Chen, Y. He, S. Murase, T. Moriarty, K. Emery, G. Li and Y. Yang, Nat. Photonics, 2012, 6, 180-185.

18 R. Tautz, E. D. Como, T. Limmer, J. Feldmann, H.J. Egelhaaf, E. von Hauff, V. Lemaur, D. Beljonne, S. Yilmaz, I. Dumsch, S. Allard and U. Scherf, Nat. Commun., 2013, 3, 1-8, DOI: 10.1038/ncomms1967.

19 P. T. Boudreault, A. Najari and M. Leclerc, Chem. Mater., 2011, 23, 456-469.

20 J. Hou, H.-Y. Chen, S. Zhang, G. Li and Y. Yang, J. Am. Chem. Soc., 2008, 130, 16144-16145.

21 Y. Liang, D. Feng, Y. Wu, S.-T. Tsai, G. Li, C. Ray and L. Yu, J. Am. Chem. Soc., 2009, 131, 7792-7799.

22 V. Gupta, N. Chaudhary, R. Srivastava, G. D. Sharma, R. Bhardwaj and S. Chand, J. Am. Chem. Soc., 2011, 133, 9960-9963.

23 C. Piliego, T. W. Holcombe, J. D. Douglas, C. H. Woo, P. M. Beaujuge and J. M. J. Frechet, J. Am. Chem. Soc., 2010, 132, 7595-7597.

24 B. Walker, A. B. Tamayo, X.-D. Dang, P. Zalar, J. Hwa Seo, A. Garcia, M. Tantiwiwat and T.-Q. Nguyen, Adv. Funct. Mater., 2009, 19, 3063-3069.
25 G. Yu, J. Gao, J. C. Hummelen, F. Wudl and A. J. Heeger, Science, 1995, 270, 1789-1791.

26 P. Attri, S. H. Lee, S. W. Hwang, J. I. Kim, S. W. Lee, G. C. Kwon, E. H. Choi and I. T. Kim, PLoS One, 2013, 88, e68970.

27 J. H. Choi, C. G. Son, Y. J. Hong, B. C. Park, H. S. Uhm and E. H. Choi, Adv. Nat. Sci.: Nanosci. Nanotechnol., 2010, 1, 045014.

28 D. H. Apaydın, D. E. Yıldı, A. Cirpana and L. Toppare, Sol. Energy Mater. Sol. Cells, 2013, 113, 100-105.

29 L. Beverina and G. A. Pagani, Acc. Chem. Res., 2014, 47, 319-327. 30 J. W. Chen and Y. Cao, Acc. Chem. Res., 2009, 42, 1709-1718.

31 M. He, M. Wang, C. Lin and Z. Lin, Nanoscale, 2014, 6, 3984-3994.

32 P. Slepicka, S. Trostova, N. S. Kasalkova, Z. Kolska, P. Sajdl and V. Svorcik, Plasma Processes Polym., 2012, 9, 197-206.

33 J. B. Pawley, Handbook of Biological Confocal Microscopy, Kluwer Academic Publishers, Dordrecht, 1995.

34 M. Schmitt, B. Leimeister, L. Baia, B. Weh, I. Zimmermann, W. Kiefer and J. Popp, ChemPhysChem, 2003, 4, 296-299.

35 J. Ouyang, Q. F. Xu, C. W. Chu, Y. Yang, G. Li and J. Shinar, Polymer, 2004, 45, 8443-8450.

36 B. Y. Ouyang, C. W. Chi, F. C. Chen, Q. Xu and Y. Yang, Adv. Funct. Mater., 2005, 15, 203-208.

37 G. P. Lopez, D. G. Castner and B. D. Ratner, Surf. Interface Anal., 1991, 17, 267-272.

38 R. Memarzadeh, F. Panahi, S. Javadpour, A. Khalafi-Nezhad, H.-B. Noh and Y.-B. Shim, Bull. Korean Chem. Soc., 2012, 33, 1297-1302.

39 W. Zhang, S. Lin, C. Wang, J. Hu, C. Li, Z. Zhuang, Y. Zhou, R. A. Mathies and C. J. Yang, Lab Chip, 2009, 9, 3088-3094.

40 K. Strzelec, N. Baczek, M. Szynkowska and J. Grams, J. Appl. Polym. Sci., 2014, 131, 40330-40339.

41 H. Hwang, H. Kim, S. Nam, D. D. C. Bradley, C. S. Ha and Y. Kim, Nanoscale, 2011, 3, 2275-2279.

42 R. H. Sestrem, D. C. Ferreira, R. Landers, M. L. A. Temperini and G. M. do Nascimento, Eur. Polym. J., 2010, 46, 484-493.

43 P. Pfluger, M. Krounbi, G. B. Street and G. Weiser, J. Chem. Phys., 1983, 78, 3212-3218.

44 F. Wang, H. Luo, Q. Wang, J. Wang and J. Xu, Molecules, 2009, 14, 4737-4746.

45 R. Li, X. Tao and X. Li, J. Mater. Chem., 2009, 19, 983-987.

46 R. Li, L. Bao and X. Li, CrystEngComm, 2011, 13, 5858-5862.

47 C. H. Chen, C. H. Hsieh, M. Dubosc, Y. J. Cheng and C. S. Hsu, Macromolecules, 2010, 43, 697-708.

48 H.-Y. Chen, J. Hou, S. Zhang, Y. Liang, G. Yang, Y. Yang, L. Yu, Y. Wu and G. Li, Nat. Photonics, 2009, 3, 649-653.

49 A. C. Fozza, J. E. Klemberg-Sapieha and M. R. Wertheimer, Plasmas Polym., 1999, 4, 183-206. 